\title{
MICROWAVE RADIATION AND ITS APPLICATION ON CONSTRUCTION MATERIALS
}

\author{
Martin PROCHÁZKA, Jindřich SOBOTKA, Karel ŠUHAJDA, Miloslav NOVOTNY \\ Faculty of Civil Engineering, Brno University of Technology, Veveři 331/95, 60200 Brno, Czech Republic \\ Received 09 February 2016; accepted 02 November 2016

\begin{abstract}
Drying structures using high-frequency electromagnetic radiation or microwave technology is currently gaining much more usage in the engineering practice. The goal of the method is the quickest elimination of water in construction (wall, floor structure, etc.). Microwave is a part of the electromagnetic radiation of frequency between $300 \mathrm{MHz}$ and $300 \mathrm{GHz}$ and wavelength between $1 \mathrm{~mm}$ and $1 \mathrm{~m}$. The frequency of $2.45 \mathrm{GHz}$ and $122 \mathrm{~mm}$ wavelength is used for engineering practice. Due to the effect of microwave radiation the divergent homogeneity of temperature field of different building materials can be observed.

This article discusses the spread of thermal field depending on the volume of water and thereby the size of mass humidity of the given material (timber). The temperature fields will be observed by a thermo camera, always after a certain time cycles of the heating.
\end{abstract}

Keywords: humidity, temperature field, microwave radiation, moisture transport, microwave drying.

\section{Introduction}

When dealing with rehabilitation of structures the need to reduce moisture, which was increased due to a defect or failure in the structure, is often necessary. With increased moisture in the construction there is a possibility of biotic pests that may subsequently affect both the life of structures and buildings but also the quality of the building's interior (Sobotka 2015).

Possible causes of an excessive increase of the water content in the structure:

- Liquidation of the flood consequences;

- Building services accidents;

- Moisture penetration from the external environment.

After subsiding or eliminating the causes there is a considerable amount of water remaining in the masonry (Fig. 1.) that must be removed, therefore quickly and effectively drying the space so it can be fully utilized once again (Sobotka 2015).

\begin{tabular}{|c|c|}
\hline Moisture rating & Masonry moisture (\% wt.) \\
\hline Very low & $<3$ \\
\hline Low & $3-5$ \\
\hline Increased & $5-7.5$ \\
\hline High & $7.5-10$ \\
\hline Very high & $>10$ \\
\hline
\end{tabular}

Fig. 1. Masonry moisture rating according to ČSN 730610

Currently there are many ways how to decrease increased water content in construction faster than naturally. The options of accelerated drying include condensation and absorption drying, heat and hot air drying, heating rods and microwave heating. Drying by microwave radiation is currently the fastest, most effective and cheapest procedure. This reduces the water content of the material based on the heating of water molecules. This structure extends the temperature field which helps faster drying of the structure. 


\section{Heat conduction in construction}

Heat transfer is defined as a transfer of heat from one substance (solid, liquid or gaseous) to another substance, both in contact, without noticeable displacement of particles (atoms, molecules or ions) forming the substance, while the character of thermal motion of the substance depends on the physical state of the substance.

\subsection{Heat flows of materials}

Fourier experiments showed that the heat Q transferred by medium incorporated between two parallel rigid plates is proportional to the area $\mathrm{A}$, their temperature difference $\left(\Theta_{1}-\Theta_{2}\right)$ and time $t$, but directly proportional to the distance of the plates $\Delta x$ (Fig. 2) (Ficker 2008).

The ability of a substance to conduct heat is quantified by a factor of proportionality (thermal conductivity) $\lambda$, which is a material constant. Fourier experimental observations served to formulate quantitative relationship later known as “The First Fourier's law of heat conduction" (Ficker 2008).

where:

$$
Q=\lambda \cdot A\left(\left(\Theta_{1}-\Theta_{2}\right) / \Delta x\right) \cdot t
$$

$\lambda$ - thermal conductivity coefficient $\left(\mathrm{Wm}^{-1} \mathrm{~K}^{-1}\right)$;

$A$ - area $\left(\mathrm{m}^{2}\right)$;

$\left(\Theta_{1}-\Theta_{2}\right)$ - temperature difference of plates $(\mathrm{K})$;

$\Delta x$ - distance of plates $(\mathrm{m})$;

$t$ - time (s).

Fourier's law is based purely on empirical observation and is not derived from other physical principles. In technical practice it is often used when calculating heat balance (losses or gains) and therefore belongs to the very basic relationships used especially in thermal engineering (Ficker 2008). a)

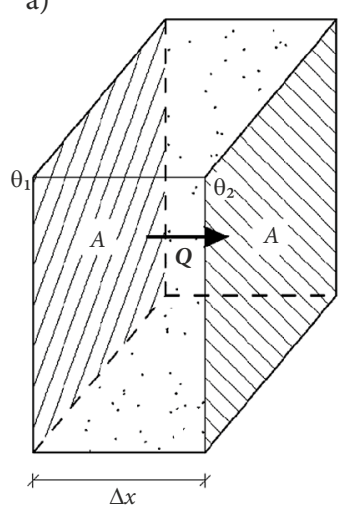

b)
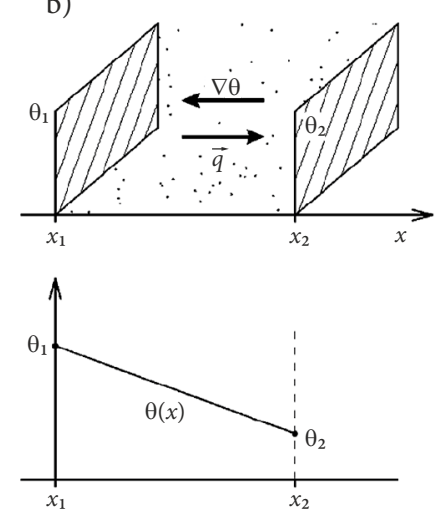

Fig. 2. Illustration of the first Fourier law: A) Heat conduction between two parallel plates; B) The temperature profile inside the wall

\subsection{Thermal conductivity coefficient}

Thermal conductivity is a property dependent only on the material composition and not to its geometric configuration. Thermal conductivity coefficient $\lambda$ is a material constant. It is numerically equal to the heat that passes through the material per unit time per unit area at a unit temperature "gradient" $(\Delta \Theta / \Delta x)$ (Ficker 2008).

\subsection{Effect of moisture on thermal conductivity}

In practice, there are three types of analytic dependence of the thermal conductivity $\lambda$ on the moisture $w$ : linear, quadratic and cubic dependence (Ficker 2008).

$$
\begin{gathered}
\lambda=\lambda_{0}+b \cdot w ; \\
\lambda=\lambda_{0}+b \cdot w+c \cdot w^{2} ; \\
\lambda=\lambda_{0}+b \cdot w+c \cdot w^{2}+d \cdot w^{3},
\end{gathered}
$$

where $\lambda_{0}, b, c, d$ are optimized to the experimental data (e.g. the method of least squares). Moisture $w$ is in these relationships expressed either by volume $w_{m}$ or weight $w_{v}$ percentage (Ficker 2008).

\section{Water and moisture in structures}

A certain percentage of moisture is contained in each solid. The amount is dependent on the temperature, moisture of the ambient air, the atmospheric conditions, porosity, pores diameter and on the shape of their walls, the quantity of hygroscopic salt in damp walls etc. (Balík 2008).

\subsection{Moisture}

Moisture of the material is an amount of water contained in porous media material. It is expressed as volume or weight ratio of water to solid phase of the material (Balík 2008).

Moisture can be divided into:

Mass moisture:

$$
w_{h}=\left(m_{w}-m_{d}\right) / m_{d}=m_{k} / m_{d},
$$

where:

$m_{w}$ - weight of wet material (g);

$m_{d}$ - weight of dry material $(\mathrm{g})$;

$m_{k}$ - weight of liquid $(\mathrm{g})$;

$w_{h}$ - mass moisture ( - , \% weight).

Volume moisture:

$W_{v}=V_{v} / V_{d}=\left(m_{w}-m_{d}\right) /\left(q_{k} \cdot V_{d}\right)=\left(w_{h} \cdot q_{d}\right) / 1000$, 
where:

$V_{v}$ - volume of free water $\left(\mathrm{m}^{3}\right)$;

$V_{d}$ - volume of dry material $\left(\mathrm{m}^{3}\right)$;

$q_{k}$ - density of water $\left(\mathrm{kg} / \mathrm{m}^{3}\right)$;

$w_{h}$ - dry material density $\left(\mathrm{kg} / \mathrm{m}^{3}\right)$;

$w_{v}$ - volume moisture ( - , \% volume).

\subsection{Water and moisture transport in porous materials}

Moisture is present in almost all building materials and thus in structures made from them. However moisture accumulation becomes difficult due to causing degradation processes and deterioration of the utility properties of the building. To avoid such situations, a proper understanding of the possibilities of binding and spreading moisture in construction materials and structures is assumed (Balík 2008).

Moisture diffusion in building materials takes place both in the gas and in the liquid phase. Diffusion is usually divided into mechanisms for water vapour diffusion and capillary liquid diffusion. While investigating the causes of increased moisture, it is necessary to analyse the proportion of forms of transport moisture into the interior of the mass of structures (Balík 2008).

One of the conditions for all moisture processes in the construction is the presence of pores in building materials. In particular the pores are open, because substances with closed pores are not subject to transport processes (Balík 2008).

\subsection{Diffusion}

In every object a certain microclimate is created, that is independent on the climate outdoors. This leads to differences between humidity and temperature in the interior and exterior. Equalizing the differences between these variables a flow of heat and moisture through building envelopes is formed. The direction of diffusive flow goes from places with higher water vapour partial pressure to an area with lower pressure. This moisture transport is called diffusion (Balík 2008).

Fick's law of the density of the mass flow of water vapour is determined as:

where:

$$
q=-\delta p \cdot \operatorname{grad} \mathrm{px},
$$

$g$ - density of mass flow of water vapour $\left(\mathrm{kg} \mathrm{m}^{-2} \mathrm{~s}^{-1}\right)$;

$p_{v}$ - actual partial pressure of water vapour $(\mathrm{Pa})$;

$\delta p$ - water vapour diffusion coefficient of relevant material (s).

\subsection{Capillary moisture conduction}

Capillary moisture conduction is typical for water-absorbent materials, which corresponds to most building materials. When contacting the material with water an intense water intake occurs, this does not depend on inclination of the pores. The height of capillary rise is affected by the pore size. Although a material with larger pores absorbs water more rapidly, the height of the capillary action is lower. In contrast, a material with smaller pores absorbs water more slowly, but the height of the capillary action is higher (Balík 2008).

Such water saturation is in building construction due to capillary conduction of water unacceptable in practice. Capillary rise of moisture is the most common way of moistening structures exposed to ground moisture (Fig. 3) (Balík 2008).

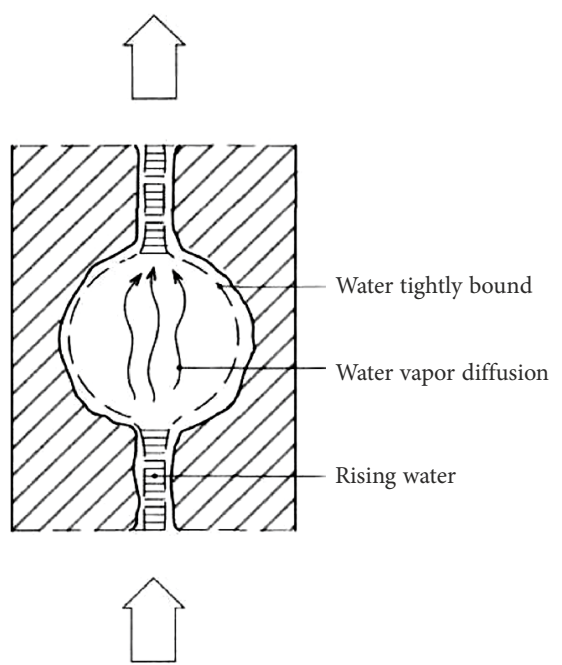

Fig. 3. Example of capillary moisture conduction

Capillary elevation is characterized by the different level of liquid in the capillary tube and the surface level in the surrounding area. This effect is caused by the capillary forces between the liquid molecules and the solid surface. Surface tension causes the liquid column moving in the capillary in the direction of the resultant of forces. In a capillary with a circular crosssection the surface tension acts at the interface of the corresponding circuit of the pores (Balík 2008).

Maximum height of capillary action in the capillaries can be expressed:

$$
h=(2 \cdot \delta \cdot \cos \Theta) /(r \cdot \rho \cdot g),
$$

where:

$\delta$ - surface tension of liquid $\left(\mathrm{Nm}^{-1}\right)$;

$\Theta$ - wetting angle between the liquid and the wall liquid $\left(^{\circ}\right)$; 
$r$ - capillary radius (m);

$\rho$ - density of liquid $\left(\mathrm{kg} \mathrm{m}^{-3}\right)$;

$g$ - gravitational acceleration $9.81 \mathrm{~ms}^{-2}$.

It is necessary to acknowledge that the actual height of the capillary action is less than the height set by calculation, as also the evaporation of moisture from the material is currently underway (Balík 2008).

\section{Microwave radiation}

Microwave is a term for a part of the electromagnetic radiation of $300 \mathrm{MHz}$ to $300 \mathrm{GHz}$ frequency, equivalent to wavelength from $1 \mathrm{~mm}$ to $1 \mathrm{~m}$. For industrial application more frequencies are permitted, but in a construction fraction the frequency of $2450 \mathrm{MHz}$ with a wavelength of $12.2 \mathrm{~cm}$ is particularly interesting. Due to microwave radiation a heating occurs and the molecules orientate according to polarity in the electric field. When the microwave radiation contacts the water molecules electromagnetic energy is transformed and heating appears. Heating of the other construction materials follows afterwards (Novotny et al. 2013).

Microwaves are a classic electromagnetic wave of a frequency lower than the solar radiation and therefore they leave no residual radiation harmful to health. Using the device is completely safe, damage to health can occur only by direct irradiation from a few $\mathrm{cm}$ for several minutes by either intentionally or improper handling machines. A device that is also used in our use in the microwave drying is for non-metallic materials, and not only that, also for disposal of mold, fungi, microorganisms, and insects (Novotny et al. 2013).

Most of all, microwave radiation of excessive strength poses a risk to human health. The use of microwave devices with radiators emitting electromagnetic radiation outside is a serious threat for people within the area of high density of microwave energy. The permissible values of electromagnetic field strength in the range of $2.45 \mathrm{GHz}$ are regulated by EU rules, including Directive 2004/40/EC, Recommendation 1999/510/EC and regulations applicable in individual countries. Usually, the regulations provide permissible strengths of electromagnetic field (from $7 \mathrm{~V} / \mathrm{m}$ to $61 \mathrm{~V} / \mathrm{m}$ ) or watt density (from $0.1 \mathrm{~W} / \mathrm{m}^{2}$ to $10 \mathrm{~W} / \mathrm{m}^{2}$ ).

The assembly used for irradiating consists of a power source, a power generator, a horn antenna and a strength indicator of the microwave radiation (Fig. 4) (Novotny et al. 2013).

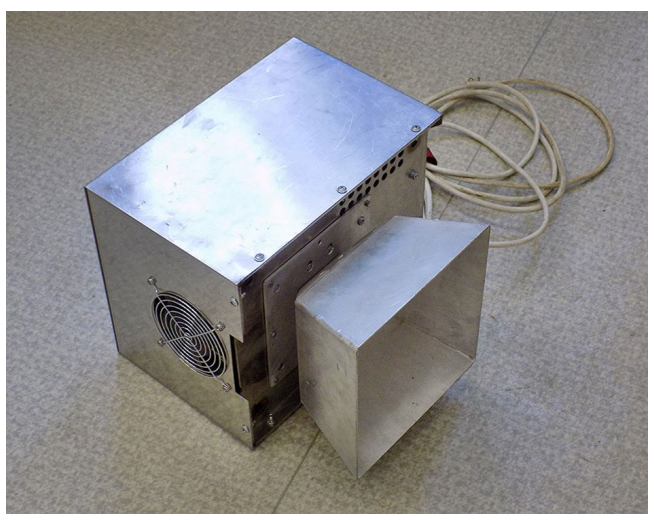

Fig. 4. Examining power generator with horn antenna

Most of the frequently used materials are transparent for the microwave electromagnetic radiation. This includes primarily ceramic, stone, concrete, wood etc. Some materials embedded in structures reflect microwaves - metals. And some of them absorb, these are mostly water and some other bipolar materials (Sobotka 2015; Novotny et al. 2013).

Speed of the drying of building structures and materials using microwave technology is greatly influenced by two factors (Novotný et al. 2014):

- Increasing the water temperature on the surface to be dried. Proportionally the number of molecules is also increased and their energy is sufficient to overcome the cohesive forces,

- Increase of water temperature inside the dried material causes an increase of its volume. Heating the water by $1{ }^{\circ} \mathrm{C}$ will increase its volume by $0.18 \%$. In normal cases, when the microwave energy treatment raises the temperature of water in the depth of the heated body of $50{ }^{\circ} \mathrm{C}$ (from $15^{\circ} \mathrm{C}$ to $65^{\circ} \mathrm{C}$ ), its volume increases by $9 \%$.

\section{Experimental measurement}

3 samples of different moisture in total were subjected to the microwave radiation (Fig. 5). Materially, it was a timber. The first drying was applied to samples that were in a long-term storage in a room with relative humidity of $51 \%$ and temperature of $20.5^{\circ} \mathrm{C}$. Prism sizes $220 \times 160 \mathrm{~mm}$ were used (Sobotka 2015; Novotný et al. 2015; Sobotka, Jiroušek 2014).

Description of experiment:

- Samples were weighted before the experiment and their humidity was measured (Table 4 ),

- Subsequently the samples were subjected to irradiation and drying (Tables 1-4, Figs 6-9). 


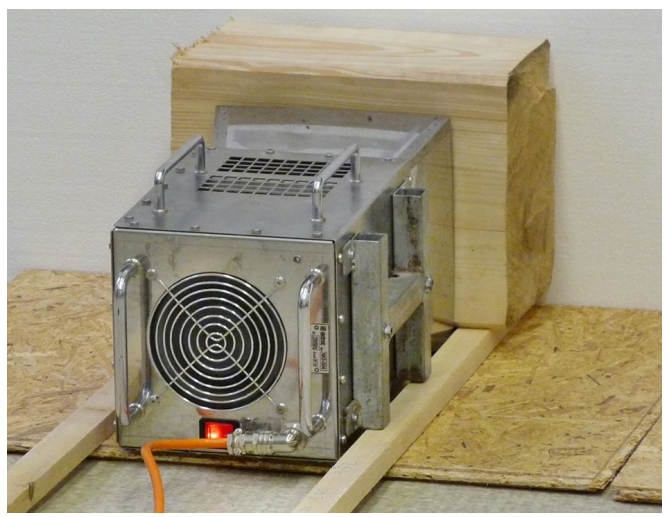

Fig. 5. Drying samples

Drying was conducted as follows (Table 1):

- 15 minutes heating;

- 120 minutes break;

- 15 minutes heating;

- 120 minutes break;

- 15 minutes heating;

- 18 hours cooling.

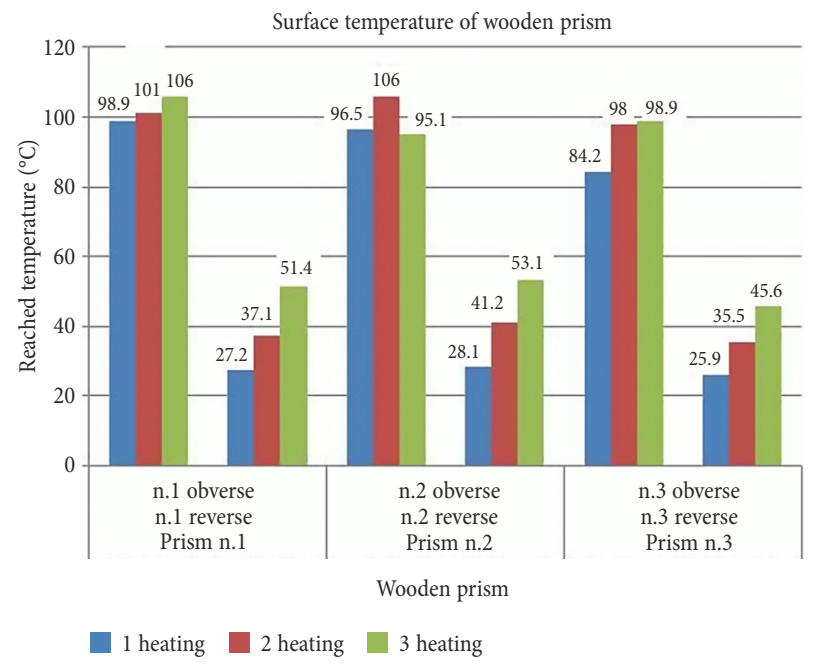

Fig. 6. Graphical representation of surface temperatures in individual heating (Fig. 7)

Table 1. Maximal sample surface temperatures, observed by a thermo camera FLIR i7

\begin{tabular}{|c|c|c|c|c|c|c|}
\hline Wooden elements & \multicolumn{2}{|c|}{ Prism n.1 } & \multicolumn{2}{c|}{ Prism n.2 } & \multicolumn{2}{c|}{ Prism n.3 } \\
\hline & n.1 obverse & n.1 reverse & n.2 obverse & n.2 reverse & n.3 obverse & n.3 reverse \\
\hline 1. heating & $98.9^{\circ} \mathrm{C}$ & $27.2^{\circ} \mathrm{C}$ & $96.5^{\circ} \mathrm{C}$ & $28.1^{\circ} \mathrm{C}$ & $84.2^{\circ} \mathrm{C}$ & $25.9^{\circ} \mathrm{C}$ \\
\hline 2. heating & $101.0^{\circ} \mathrm{C}$ & $37.1^{\circ} \mathrm{C}$ & $106.0^{\circ} \mathrm{C}$ & $41.2^{\circ} \mathrm{C}$ & $98.0^{\circ} \mathrm{C}$ & $35.5^{\circ} \mathrm{C}$ \\
\hline 3. heating & $106.0^{\circ} \mathrm{C}$ & $51.4^{\circ} \mathrm{C}$ & $95.1^{\circ} \mathrm{C}$ & $53.1^{\circ} \mathrm{C}$ & $98.9^{\circ} \mathrm{C}$ & $45.6^{\circ} \mathrm{C}$ \\
\hline
\end{tabular}

Table 2. Temperatures inside samples, measured in pre-drilled holes (from the rear side) by inner tined thermometer (Fig. 8)

\begin{tabular}{|c|c|c|c|c|c|c|}
\hline Wooden elements & \multicolumn{2}{|c|}{ Prism n.1 } & \multicolumn{2}{c|}{ Prism n.2 } & \multicolumn{2}{c|}{ Prism n.3 } \\
\hline & $\begin{array}{c}\text { Internal } \\
\text { temperature of } \\
\text { prism n.1-I. }\end{array}$ & $\begin{array}{c}\text { Internal } \\
\text { temperature of } \\
\text { prism n.1-II. }\end{array}$ & $\begin{array}{c}\text { Internal } \\
\text { temperature of } \\
\text { prism n.2-I. }\end{array}$ & $\begin{array}{c}\text { Internal } \\
\text { temperature of } \\
\text { prism n.2-II. }\end{array}$ & $\begin{array}{c}\text { Internal } \\
\text { temperature of } \\
\text { prism n.3-I. }\end{array}$ & $\begin{array}{c}\text { Internal } \\
\text { temperature of } \\
\text { prism n.3-II. }\end{array}$ \\
\hline 1. heating & $27.7^{\circ} \mathrm{C}$ & $31.7^{\circ} \mathrm{C}$ & $27.0^{\circ} \mathrm{C}$ & $30.2^{\circ} \mathrm{C}$ & $16.6^{\circ} \mathrm{C}$ & $49.8^{\circ} \mathrm{C}$ \\
\hline 2. heating & $62.9^{\circ} \mathrm{C}$ & $74.4^{\circ} \mathrm{C}$ & $58.4^{\circ} \mathrm{C}$ & $64.8^{\circ} \mathrm{C}$ & $37.2^{\circ} \mathrm{C}$ & $45.4^{\circ} \mathrm{C}$ \\
\hline 3. heating & $86.6^{\circ} \mathrm{C}$ & $94.7^{\circ} \mathrm{C}$ & $95.1^{\circ} \mathrm{C}$ & $97.2^{\circ} \mathrm{C}$ & $48.5^{\circ} \mathrm{C}$ & $58.4^{\circ} \mathrm{C}$ \\
\hline
\end{tabular}

Table 3. Representation of samples humidity, measured by MOIST 210b device

\begin{tabular}{|c|c|c|c|c|c|c|}
\hline Wooden elements & \multicolumn{2}{|c|}{ Prism n.1 } & \multicolumn{2}{c|}{ Prism n.2 } & \multicolumn{3}{c|}{ Prism n.3 } \\
\hline & n.1 obverse & n.1 reverse & n.2 obverse & n.2 reverse & n.3 obverse & n.3 reverse \\
\hline Initial & $17.1 \%$ & $18.1 \%$ & $17.7 \%$ & $18.5 \%$ & $18.5 \%$ & $22.0 \%$ \\
\hline 120 minutes after heating & $11.2 \%$ & $14.9 \%$ & $19.0 \%$ & $17.6 \%$ & $16.9 \%$ & $20.0 \%$ \\
\hline
\end{tabular}

Table 4. Representation of sample weights / weight loss after irradiation (Fig. 9)

\begin{tabular}{|c|c|c|c|}
\hline Wooden elements & Prism n.1 & Prism n.2 & $7955 \mathrm{~g}$ \\
\hline Initial & $5754 \mathrm{~g}$ & $5887 \mathrm{~g}$ & $7318 \mathrm{~g}$ \\
\hline 18 hours after drying & $5449 \mathrm{~g}$ & $5428 \mathrm{~g}$ & $637 \mathrm{~g}$ \\
\hline Weight loss & $305 \mathrm{~g}$ & $459 \mathrm{~g}$ & $\mathrm{n}$ \\
\hline
\end{tabular}



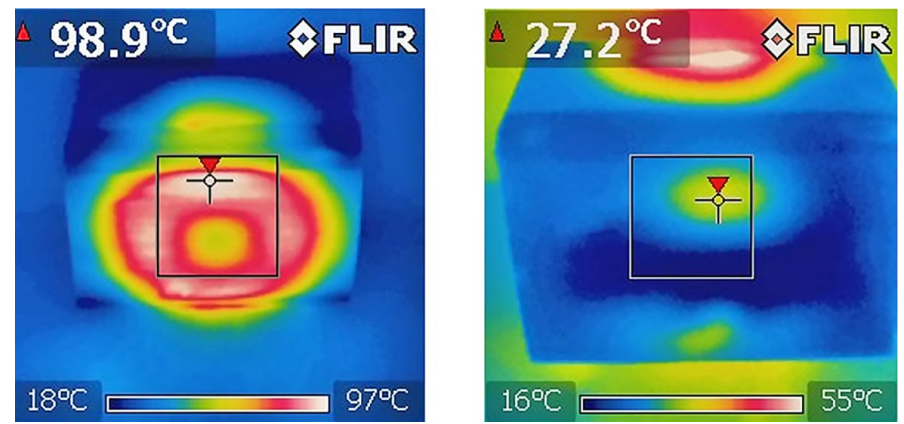

Fig. 7. Example of thermo vision images of prism n.1 after first heating from reverse and obverse side

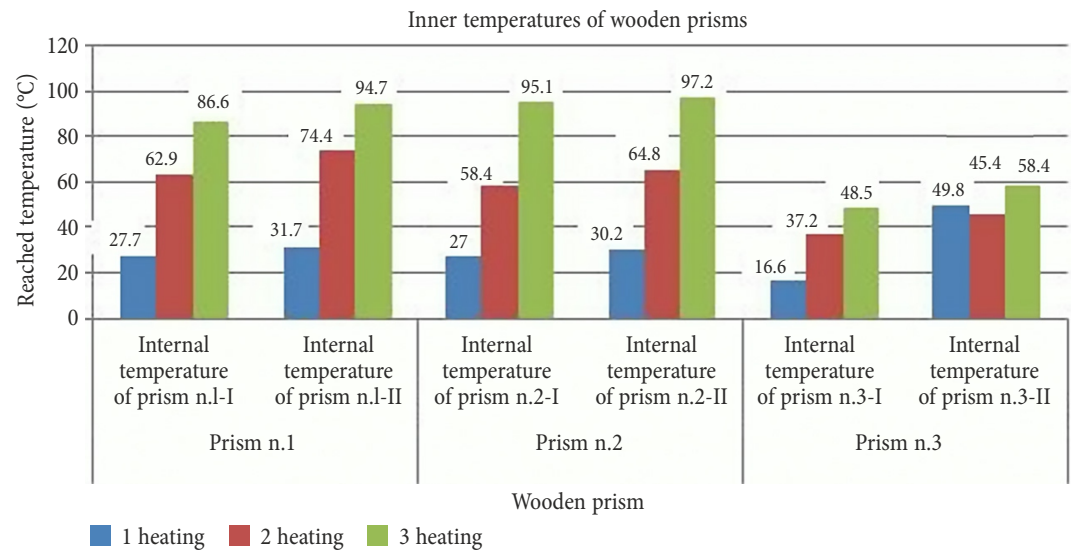

Fig. 8. Graphical representation of surface temperatures in individual heating

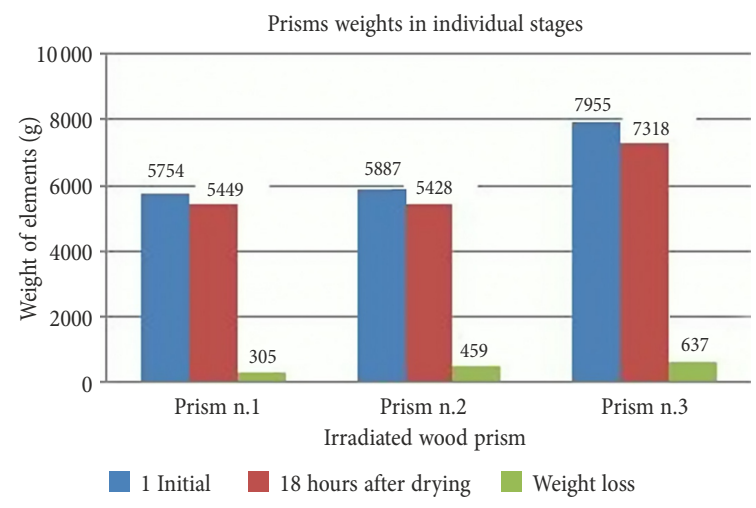

Fig. 9. Graphical representation of sample weights/weight loss after irradiation

\section{Conclusions}

The aim was to determine the effect of higher initial humidity of the irradiated material on the penetration of microwave energy and heating rate. The test samples were of sawn timber in "raw" state. There were large differences measured between temperatures at the front and the back side of the experimental prisms. After final cooling shape deformation and creating of more drying cracks were evident.

\section{Acknowledgement}

Project of University specific research FAST-S-16-3345 "Verification of behaviour and development of structures and structural elements and combined structures from wood and reinforced concrete", Faculty of Civil Engineering, Brno University of Technology.

\section{References}

Balík, M. 2008. Building dehumidification. Prague: Grada.

ČSN 73 0610. Waterproofing of buildings. Czech Office for Normalization, Praha, 2000.

Directive 2004/40/EC of the European Parliament and of the Council of 29 April 2004 on the minimum health and safety requirements regarding the exposure of workers to the risks arising from physical agents (electromagnetic fields) (18th individual Directive within the meaning of Article 16(1) of Directive 89/391/EEC), Official Journal of the European Union, 2004.

EU Council Recommendation 1999/510/EC, Official Journal of the European Union, 1999.

Ficker, T. 2008. Applied physics: heat conduction in constructions. VUT FAST, Brno.

Novotny, M.; Skramlik, J.; Suhajda, K.; Tichomirov, V. 2013. Sterilization of biotic pests by microwave radiation, Procedia Engineering 57: 1094-1099.

https://doi.org/10.1016/j.proeng.2013.04.138 
Novotný, M.; Šuhajda, K.; Sobotka, J.; Gintar, J. 2014. Use of EMW radiation in the building industry, Advanced Materials Research 1041: 297-302. https://doi.org/10.4028/www.scientific.net/amr.1041.297

Novotný, M.; Šuhajda, K.; Sobotka, J.; Jiroušek, Z. 2015. Drying technologies in masonry structures, Advanced Materials Research 1122: 65-69.

https://doi.org/10.4028/www.scientific.net/amr.1122.65
Sobotka, J. 2015. Physical values in technology dry masonry buildings, in JUNIORSTAV 2015, 29 January 2015, Brno, Czech Republic.

Sobotka, J.; Jiroušek, Z. 2014. Wooden elements remediation of Kittel house, Materiály pro stavbu. Prague: Business Media CZ, s.r.o.

Martin PROCHÁZKA, Ing. He acquired Master's degree at Faculty of Civil Engineering, Brno University of Technology, in 2014. Nowadays he is a student of doctoral study programme. His research is focused on Analysis of the destruction of biotic pests, which he has several time disscused at international conferences.

Jindřich SOBOTKA, Ing., PhD. He acquired Master's degree at Faculty of Civil Engineering, Brno University of Technology, in 2010, and doctoral study programme in 2015. Nowadays he is a assistent Faculty of civil engineering, Brno university of technology. His research is focused on destruction of biotic pests and building dehumidification, which he has several time disscused at international conferences.

Karel ŠUHAJDA. Dr, Ing., PhD. Faculty of Civil Engineering, Brno University of Techhnology. Research interests: theory and structural engineering constructions.

Miloslav NOVOTNY. Professor of the Faculty of Civil Engineering, Brno University of Techhnology. Research interests: issues involved with timber structures, the roof structures of buildings i.e. wooden load-bearing structures as well as sheet and sectional coverings, failures and reconstructions of buildings with a focus on the remediation of dampness in timber, and the application of the possible use of microwave radiation in construction practice. 